\title{
Endophytic actinomycetes: promising source of novel bioactive compounds
}

\author{
Atsuko Matsumoto and Yōko Takahashi \\ Endophytic actinomycetes associated with plant roots are a relatively untapped source of potential new bioactive compounds. \\ This is becoming increasingly important, as the returns from discovery research on soil-dwelling microbes, have been \\ continuously diminishing. We have isolated more than 1000 strains of actinomycetes from plant roots in our search for \\ novel bioactive compounds, identified and assayed their bioactive metabolites, as well as investigated their biosynthetic genes \\ for generating secondary metabolites. This has resulted in the discovery of several interesting compounds. Creation of plant \\ root clone libraries enabled us to confirm that we had, indeed, isolated endophytes. In this paper, we introduce our approach \\ to this promising line of research, incorporating data from other publications, and illustrate the potential that endophytic \\ actinomycetes offer as a new source of novel lead compounds. \\ The Journal of Antibiotics (2017) 70, 514-519; doi:10.1038/ja.2017.20; published online 8 March 2017
}

\section{INTRODUCTION}

Natural products have been the source of the world's most important bioactive compounds and microorganisms are a primary resource driving drug discovery. ${ }^{1,2}$ Although numerous actinomycetes have been isolated, and used as producer of key drugs and biomedical agents, it has lately become increasingly difficult to find novel compounds as well as to avoid time- and resource-consuming repeated detection of known compounds. Consequently, it is extremely advantageous to be able to investigate Nature's hitherto untapped microbial organisms. In order to achieve this objective, we have been isolating actinomycetes using various methods from a diverse samples of natural environments, including endophytic microbes which live in plants. It is well known that many kinds of bacteria live in and around plant roots, including the phyla Proteobacteria, Actinobacteria (Gram-positive high G+C bacteria), Bacteroides and Verrucomicrobia, which have been detected by pyrosequencing. ${ }^{3-5}$ Over 40 genera of filamentous Actinobacteria (actinomycetes) have been detected from Triticum aestivum roots alone by terminal restriction fragment length polymorphism. ${ }^{6}$ Bacteria exist on the surface and inside of plant roots, as demonstrated by fluorescence in situ hybridization, scanning electron microscopy or detection of target genes. ${ }^{7-10}$ Numerous bacteria live in rhizospheres, up to $10^{6}$ cells per $\mathrm{mm}^{3}$, including filamentous bacteria with actinomycetes accounting for an estimated $4 \%$ of the total. ${ }^{9}$

This shows the relationship that exists between actinomycetes and plants. Janso and Carter isolated 123 actinomycete strains from 256 tissue samples (leaves, roots, stems, etc.) collected from 113 plants and they were categorized on the basis of $16 \mathrm{~S}$ rRNA gene sequences into six families; Streptosporangiaceae (40\%), Streptomycetaceae (27\%), Thermomonosporaceae (16\%), Micromonosporaceae (8\%), Pseudonocardiaceae
(8\%) and Actinosynnemataceae (2\%). ${ }^{11}$ Notably, the genus Streptomyces in the family Streptomycetaceae accounted for only $26 \%$, meaning that rare actinomycetes (non-Streptomyces) make up 74\% of the total and other reports also indicated that rare actinomycetes are majority in plant, ${ }^{12-14}$ although Kaewkla and Franco reported that Streptomyces strains accounted for $72 \%$ of endophytic actinomycetes isolated from Australian native trees. ${ }^{15}$

It remains to be seen whether this promising new source of bioactive materials will bear fruit, but the signs are promising. Evaluation of the presence of genes coding for polyketide synthase (PKS) or nonribosomal peptide synthetase (NRPS) have been frequently carried out and a few reports found, as an indicator, that $21-66 \%, 45-82 \%$ and $33-100 \%$ of endophytic actinomycetes have type I PKS (PKS-I), type II PKS (PKS-II) and NRPS, respectively. ${ }^{11,12,14}$ It is widely believed that the potential of secondary metabolites with biological activities from endophytic actinomycetes is just as great as that achieved from soil actinomycetes. ${ }^{16-20}$ As results of our exploration, we have already found several novel compounds from endophytic actinomycetes. In a similar vein, many new genera of actinomycetes, such as Allonocardiopsis from the fruit of a medical plant, ${ }^{21}$ Actinophytocola from Thai glutinous roots of rice plants, ${ }^{22}$ Plantactinospora from root of a medical plant, ${ }^{23}$ had been discovered and promising endophytes with unknown function may arise from plants. In this paper, we will outline our approach to the isolation of endophytic actinomycetes from plant roots and the evaluation of their potential for producing useful bioactive compounds.

\section{ISOLATION OF ACTINOMYCETES FROM PLANT ROOTS}

We employed the following isolation method for our isolation of actinomycete strains from plant roots; the roots were washed with $70 \%$ 


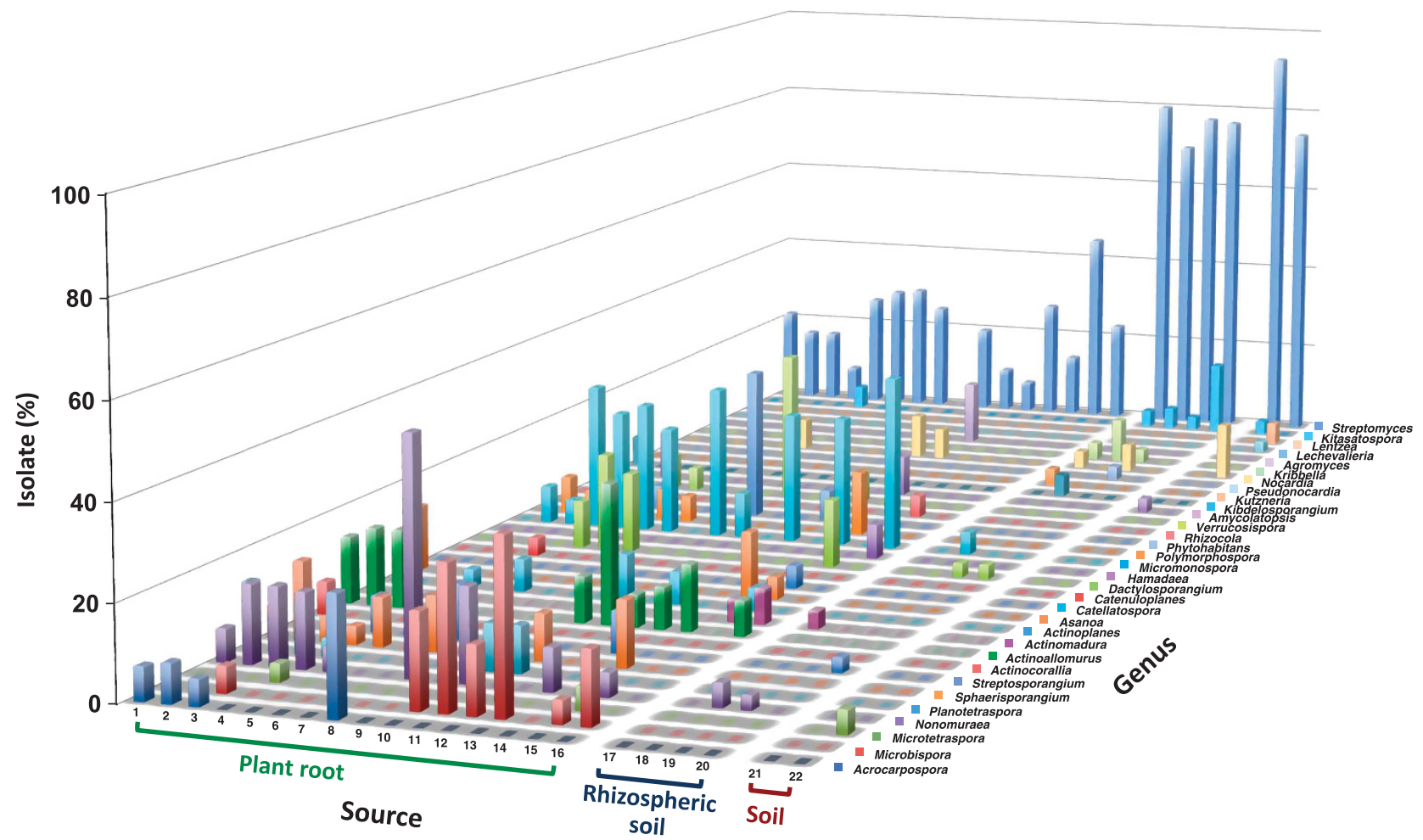

Figure 1 Classification of actinomycetes isolated from plant root and soil samples. Isolating source: 1-3; Mondo grass (Ophiopogon japonicus ker-Gawler), 4-7; Kinginso (Goody procera), 8-9; Common Sorrel (Rumex acetosa), 10; Chusan Palm (Trachycarpus fortuneI), 11; Mugwort (Artemisia indica var. maximowiczi), 12; Dokudami (Houttuynia), 13; Prickly Sow-thistle (Sonchus asper), 14; Fuki (Petasites japonicus), 15; Hellebore (Helleborus orientalis), 16; Pteridophyta, 17-18; Surface soil of Mondo grass, 19-20; Surface soil of Kinginso, 21; Soil at the depth of $1 \mathrm{~cm}$, 22; and Soil at the depth of $5 \mathrm{~cm}$.

Table 1 Antimicrobial activity of cultured broths of isolates from plant roots and rhizospheric soils

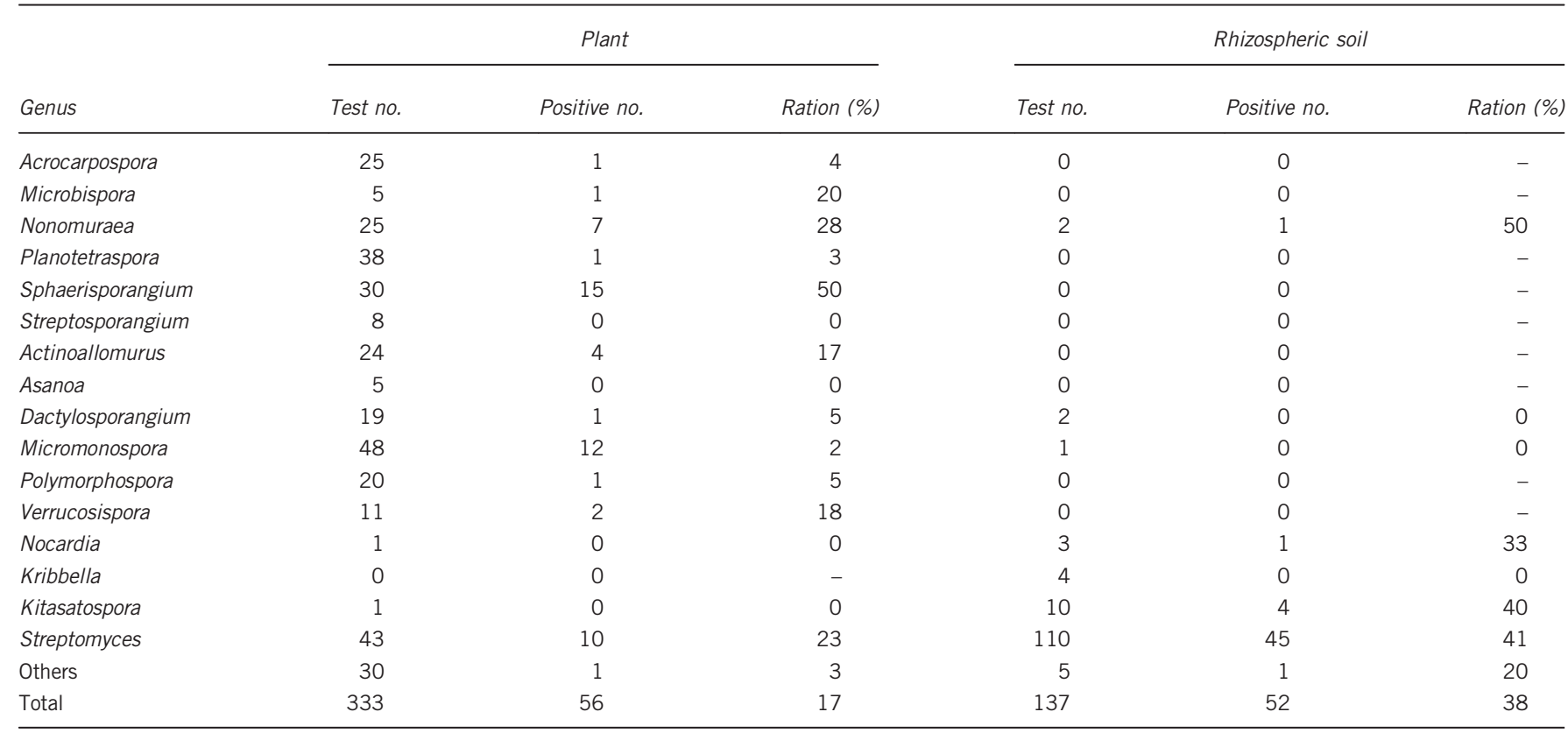

Antimicrobial activities against at least one of six tested microorganisms; Bacillus subtilis KB-211, Kocuria rhizophila KB-212, Escherichia coli KB-213, Xanthomonas campestris pv. oryzae KB-88, Candida albicans KF-1 and Mucor racemosus KF-223.

ethanol, $1 \%$ sodium hypochlorite and sterilized water and then dried, thereafter the samples were ground with a pestle and mortar. The diluted samples were mixed with water proline agar (WPA;
$1.0 \%$ proline, $1.5 \%$ agar, tap water, $\mathrm{pH}$ not adjusted) or/and CMC agar $(1.0 \%$ carboxymethyl cellulose sodium salt, $0.1 \%$ L-asparagine, $0.1 \% \quad \mathrm{~K}_{2} \mathrm{HPO}_{4}, \quad 0.0001 \% \quad \mathrm{FeSO}_{4} \cdot 7 \mathrm{H}_{2} \mathrm{O}, \quad 0.0001 \% \quad \mathrm{MnCl}_{2} \cdot 4 \mathrm{H}_{2} \mathrm{O}$, 
$0.0001 \% \mathrm{ZnSO}_{4} \cdot 7 \mathrm{H}_{2} \mathrm{O}, 1.5 \%$ agar, $\left.\mathrm{pH} 7.0\right)$ containing nalidixic acid $\left(25 \mu \mathrm{g} \mathrm{ml}^{-1}\right)$ and benomyl $\left(20 \mu \mathrm{g} \mathrm{ml}^{-1}\right)$. After cultivation for 1-3 months at $27^{\circ} \mathrm{C}$, approximately $10^{2}-10^{5}$ colonies appeared per $1 \mathrm{~g}$ of each dried sample. These results confirmed that a lot of culturable bacteria can be found in plant roots. For practical reasons, we narrowed down the isolation system to concentrate on actinomycetes. Consequently, we have isolated a variety of actinomycete strains, comprising more than 1000 from various kinds of roots. To further focus our work, 642 actinomycetes we isolated from 16 plant samples were classified into 32 genera of 9 families on the basis of $16 \mathrm{~S}$ rRNA gene partial sequence analyses. They were identified with species showing the highest similarity values by BLAST search, and the number of species was summed up on each sample. For comparative purposes, actinomycetes isolated from rhizospheric soils and general soils were also classified by the same method. Figure 1 shows the genera to which the strains from each plant belonged, as well as the proportion of isolates from each genus. Streptomyces strains isolated from plant samples accounted for only $22.9 \%$, while the isolate figures from rhizospheric soils and general soil samples were $84.0 \%$ and $84.1 \%$, respectively. It is well known that soil samples are certainly a rich repository of Streptomyces species, more than 500 of which have been described. Yet it is, perhaps, of far greater significance that nonStreptomyces, i.e., rare actinomycete, strains are isolated from plant material with high frequency. The classification results of isolates from plant roots, rhizospheric and general soil samples reveal that specific strains belonging to various genera could be isolated from plant roots but not from soil. It is thought that the appearance of rare actinomycete strains is inhibited in soil by the existence of fastgrowing Streptomyces strains but this is not the case in plant roots which the ratio of Streptomyces is low. Therefore, it seems that plant roots are very good potential source of rare actinomycete strains and, probably, new secondary metabolites.

As a result of our on-going research, we have already reported three new genera, Phytohabitans, Rhizocola and Actinorhabdospora, and 10 new species, ${ }^{24-31}$ and we fully expect to find more as-yet undiscovered species in the near future.

\section{POTENTIAL OF SECONDARY METABOLITES PRODUCED BY ENDOPHYTIC ACTINOMYCETES}

Productive capacity for antibiotics

The capability of isolates to generate antibacterial and antifungal compounds was investigated by the paper disc method using cultured broth samples of 333 strains from plant roots and 137 strains from rhizospheric soils. Some $8.5 \%$ of isolates from plant roots showed antimicrobial activity against Bacillus subtilis KB-211, 9.1\% against Kocuria rhizophila KB-212, 5.7\% against Xanthomonas campestris pv. oryzae KB-88, 3.4\% against Mucor racemosus KF-223, 1.7\% against Candida albicans KF-1 but no action at all against Escherichia coli KB-213, while isolates from rhizospheric soils were 20.3, 17.1, 8.9, 21.1, 9.8 and $8.1 \%$, respectively. This indicates that isolates from rhizospheric soil have a better prospect of producing antimicrobial compounds than organisms from plant roots. Table 1 shows the positive antimicrobial activity in six tested microorganisms. Although antimicrobial activity of the isolates from plant roots was generally worse than that of soil-dwelling organisms, $50 \%$ of Sphaerisporangium strains, which were not isolates from rhizospheric soil performed bioactivity, additionally, the genera Microbispora, Actinoallomurus, Verrucosispora and others also produced antibiotics. Pozzi et al. ${ }^{32}$ concluded that Actinoallomurus strains produce antibiotic compounds at high frequency, and Tiwari et al. ${ }^{33}$ reported that rare actinomycetes possess the capacity to produce many useful metabolites and represent
Table 2 Strain numbers of biosynthetic genes in Streptomyces and rare actinomycete strains

\begin{tabular}{lcccc}
\hline Source & Strain no. & PKS-I & NRPS & PKSE \\
\hline $\begin{array}{l}\text { Streptomyces } \\
\quad \text { Plants }\end{array}$ & 8 & $3(38)$ & $8(100)$ & $1(13)$ \\
Soils & 37 & $34(92)$ & $34(92)$ & $3(8)$ \\
& & & & \\
Non-Streptomyces & & & & \\
$\quad$ Plants & 108 & $74(69)$ & $108(100)$ & $59(55)$ \\
$\quad$ Soils & 57 & $34(60)$ & $46(81)$ & $12(21)$ \\
\hline
\end{tabular}

Abbreviations: NRPS, nonribosomal peptide synthetase; PKS-I, type I polyketide synthase; PKSE, enediyne biosynthesis PKS.

one of the most important sources of new bioactive compounds. We are very interested in endophytic actinomycete strains which is difficult to isolate from the soil. Thus, plants provide access to unique actinomycete strains, which we expect to have a high potential to produce novel bioactive compounds.

\section{Secondary metabolite biosynthetic genes}

We attempted to detect the PKS-I, NRPS and enediyne biosynthesis PKS (PKSE) genes in strains isolated from plant roots, as well as from soils, using modification of the previous PCR methods. ${ }^{34,35}$ In Streptomyces strains, the PKS-I gene in isolates from plant roots $(38 \%)$ was found far less than in isolates from soils (92\%), while there was little difference in the percentage of NRPS and PKSE genes detected. In rare actinomycetes, PKSE genes from plant root isolates $(55 \%)$ were more than those detected in soil isolates (21\%; Table 2$)$. The appearance of these specific biosynthetic genes indicates the high potential of endophytic actinomycetes for producing attractive bioactive secondary metabolites. We expect that endophytic actinomycetes will probably produce significantly different metabolites from soil-dwelling actinomycetes.

\section{ENDOPHYTIC BACTERIA IN PLANTS}

Our observations of Actinobacteria containing actinomycetes in plant roots by fluorescence in situ hybridization (FISH) using Actinobacteriaspecific probes showed that they appear to be found in tissue toward the exterior surfaces, which corresponds with other reports (data not shown). ${ }^{7,8,10}$ Furthermore, in comparison of the colony formation from outer and inner part of tissues using two kinds of plant roots, $10^{7}$ $\mathrm{CFU} \mathrm{g}^{-1}$ (dried sample) from near the exterior and $10^{3}-10^{5} \mathrm{CFU} \mathrm{g}^{-1}$ (dried sample) from the inside tissue of both samples were detected. The data supported the results detected by FISH. It was therefore surmised that most endophytic actinomycetes inhabit in the outer part of plant roots.

To estimate how many we are able to isolate and culture endophytic Actinobacteria, we constructed a $16 \mathrm{~S}$ rRNA gene clone library of endophytic Actinobacteria and compared isolates with clones based on their sequences. Material obtained from the roots of Achyranthes bidentata was used for both isolation of Actinobacteria and construction of the clone library. All bacteria colonies, including filamentous bacteria (actinomycetes), were picked up and non-filamentous bacteria were confirmed by amplification of Actinobacteria-specific band of $23 \mathrm{~S}$ rRNA gene to determine whether Actinobacteria or not. ${ }^{36}$ The bacterial DNA in tissue samples were extracted using PowerSoil DNA Isolation Kit (MO BIO), and the Actinobacteria 16S rRNA gene sequence was amplified with Actinobacteria-specific primers Act-235F (5'-CGC GGC CTA TCA GCT TGT TG-3') and Act-878R $\left(5^{\prime}\right.$-CCG TAC TCC CCA GGC GGG G-3'), ${ }^{37}$ for the construction 
Table 3 Actinomycetes in roots of Achyranthes bidentata estimated by isolates and clone library

\begin{tabular}{|c|c|c|c|c|}
\hline \multirow[b]{2}{*}{ Genus } & \multicolumn{2}{|c|}{ Isolate } & \multicolumn{2}{|c|}{ Clone } \\
\hline & Number & $\%$ & Number & $\%$ \\
\hline Aciditerrimonas & 0 & 0 & 13 & 5.7 \\
\hline Actinoallomurus & 1 & 0.6 & 0 & 0 \\
\hline Actinokineospora & 1 & 0.6 & 1 & 0.4 \\
\hline Actinomadura & 0 & 0 & 1 & 0.4 \\
\hline Actinomycetospora & 1 & 0.6 & 0 & 0 \\
\hline Actinophytocola & 0 & 0 & 8 & 3.5 \\
\hline Aeromicrobium & 0 & 0 & 2 & 0.9 \\
\hline Agreia pratensis & 0 & 0 & 1 & 0.4 \\
\hline Agrococcus terreus & 0 & 0 & 1 & 0.4 \\
\hline Amycolatopsis & 0 & 0 & 1 & 0.4 \\
\hline Arthrobacter & 0 & 0 & 7 & 3.1 \\
\hline Asanoa & 0 & 0 & 2 & 0.9 \\
\hline Catenulispora & 0 & 0 & 3 & 1.3 \\
\hline Catellatospora & 2 & 1.2 & 1 & 0.4 \\
\hline Cellulomonas & 0 & 0 & 2 & 0.9 \\
\hline Cellulosimicrobium & 1 & 0.6 & 0 & 0 \\
\hline Conexibacter & 0 & 0 & 1 & 0.4 \\
\hline Friedmanniella & 0 & 0 & 2 & 0.9 \\
\hline Geodermatophilus & 0 & 0 & 1 & 0.4 \\
\hline Herbiconiux & 0 & 0 & 1 & 0.4 \\
\hline lamia & 1 & 0.6 & 2 & 0.9 \\
\hline Ilumatobacte & 0 & 0 & 6 & 2.6 \\
\hline Isoptericola & 3 & 1.8 & 0 & 0 \\
\hline Jatrophihabitans & 0 & 0 & 2 & 0.9 \\
\hline Kibdelosporangium & 0 & 0 & 20 & 8.8 \\
\hline Kineosporia & 0 & 0 & 1 & 0.9 \\
\hline Klugiella & 0 & 0 & 1 & 0.9 \\
\hline Kribbella & 0 & 0 & 1 & 0.9 \\
\hline Lechevalieria & 1 & 0.6 & 0 & 0 \\
\hline Lentzea & 0 & 0 & 11 & 4.8 \\
\hline Marmoricola & 0 & 0 & 3 & 1.3 \\
\hline Microbacterium & 9 & 5.4 & 10 & 4.4 \\
\hline Microlunatus & 0 & 0 & 2 & 0.9 \\
\hline Micromonospora & 0 & 0 & 3 & 1.3 \\
\hline Micropruina & 0 & 0 & 2 & 0.9 \\
\hline Modestobacter & 0 & 0 & 1 & 0.4 \\
\hline Mycobacterium & 18 & 10.8 & 24 & 10.6 \\
\hline Nocardioides & 4 & 2.4 & 6 & 2.6 \\
\hline Nonomuraea & 5 & 3 & 0 & 0 \\
\hline Oerskovia & 6 & 3.6 & 0 & 0 \\
\hline Phytohabitans & 0 & 0 & 5 & 2.2 \\
\hline Planosporangium & 0 & 0 & 1 & 0.4 \\
\hline Promicromonospora & 1 & 0.6 & 13 & 5.7 \\
\hline Pseudonocardia & 0 & 0 & 18 & 7.9 \\
\hline Rhodococcus & 0 & 0 & 4 & 1.8 \\
\hline Saccharothrix & 0 & 0 & 5 & 2.2 \\
\hline Salinibacterium & 0 & 0 & 2 & 0.9 \\
\hline Solirubrobacter & 0 & 0 & 1 & 0.4 \\
\hline Streptomyces & 111 & 66.9 & 24 & 10.6 \\
\hline Streptosporangium & 0 & 0 & 1 & 0.4 \\
\hline Virgisporangium & 0 & 0 & 5 & 2.2 \\
\hline Williamsia & 1 & 0.6 & 0 & 0 \\
\hline Total & 166 & 100 & 227 & 100 \\
\hline
\end{tabular}

of clone library. The 16S rRNA gene partial sequences of 166 isolates and 227 clones were analyzed and the genera were identified (Table 3). Results suggest 44 genera of Actinobacteria were detected in clones while actinomycetes belonging to only 16 genera were isolated. Furthermore, the genus Phytohabitans which presently comprised only five species isolated from plant samples ${ }^{24,30,38}$ were detected only in the clone library. Kibdelosporangium strains isolated in the past from both plant roots and rhizospheric soils were not isolated in this case although those $16 \mathrm{~S}$ rRNA genes were detected (8.8\%). It may be caused by appearance of the 111 Streptomyces strains included $48 \mathrm{~S}$. fragilis and 39 S. xiamenensis strains. In addition, the genera Iamia, Ilumatobacter and Solirubrobacter, which are positioned deeply in the lineage of the class Actinobacteria and presently comprise only a few species, are extremely rare but we managed to obtain their clones.

There is a significantly high possibility that many as-yet-uncultured Actinobacteria exist. However, as there are more easily-culturable actinomycetes, it may be advisable to concentrate our discovery efforts using them, at least initially so that we can establish and optimize culturing media and methods.

\section{SEARCH FOR NOVEL COMPOUND FROM ENDOPHYTIC ACTINOMYCETES}

We have isolated a lot of rare actinomycete strains from plant root samples. However, it is difficult to find new bioactive compounds produced by them because the growth of the strains is generally slow and the metabolites they produce are often less than those produced by Streptomyces strains. As one of the methods compensating for the demerit, we introduced search for new compounds based on the physico-chemical properties of the secondary metabolites produced by endophytic actinomycetes. As a result, we found the actinoallolides which are 12-membered macrolides in a cultured broth of Actinoallomurus fulvus MK10-036, the trehangelins which consist of two trehalose molecules and an angelic acid from Polymorphospora rubra K07-0510, and the spoxazomicins, pyochelin family antibiotics from Streptosporangium oxazolinicum K07-0460 ${ }^{\mathrm{T}} .^{39-41}$ Furthermore, we have cultured 22 endophytic actinomycetes, which were isolated from eight kinds of plant and classified in 12 genera. The HPLC analyses of their culture broths extracted by ethyl acetate indicated that aranciamycins were produced in seven strains, belonging to the genera Sphaerisporangium, Kibdelosporangium, Planomonospora and Actinophytocola, and their cultured broths displayed antibacterial activity against Xanthomonas campestris pv. oryzae $\mathrm{KB}-88$, which is a known plant pathogen. Endophytes are therefore capable of generating anthraquinone antibiotics although we do not know why aranciamycins are commonly produced by different strains from differing plants. We presume they are produced as defensive chemicals to protect against antagonistic organisms.

It is clear that the relatively unexplored range of endophytic actinomycetes could be a rich source of novel bioactive compounds, in comparison with the compounds that have been identified from soil-dwelling actinomycetes.

\section{CONCLUDING REMARKS}

Natural products originating from microorganisms are a proven important source for the discovery of new bioactive compounds. Since the beginning of antibiotics discovery, we have aimed to isolate as many actinomycetes as possible, and soil samples have been the primary source exploited in this respect. Use of biosynthetic genes rather than cultivation of organisms has been intensified and accelerated to help overcome the problem of unculturable bacteria. However, there are enormous untapped resources remained. To fully 
realize the potential of these treasure troves, we have concentrated our efforts to isolate untapped microorganisms using various innovatory and diverse methods, media and cultivation practices. This flexible and novel approach has, for example, allowed us to obtain the mangromicins, which have a unique cyclopentadecane structure from Lechevalieria aerocolonigenes K10-0216, which originated in mangrove soil, the lariatins that have a lasso structure from Rhodococcus jostii K01-B0171, and actinohivin that displays anti-HIV activity from Longispora albida $\mathrm{K} 97-0003^{\mathrm{T}}$ which was isolated using a gellan gum medium instead of agar. ${ }^{42-44}$ These producing strains are rare actinomycetes which occasionally produce different metabolites from Streptomyces strains. Most of actinomycetes producing enediyne antibiotics are also rare actinomycetes, such as Micromonospora strain which produce dynamicin and Actinomadura strain which produce maduropeptin. ${ }^{45,46}$ The facts are supported by the appearance of PKSE gene with high frequency from rare actinomycetes (Table 2). They are one of useful and attractive source of new bioactive compounds.

We decided to focus attention on endophytes as a prospective new source of novel microbes because the taxa of actinomycetes in plant roots has proven to be significantly different from those found in soil environments. At present, genome sequence analyses are easily carried out and many biosynthetic genes of functional molecules have been identified, furthermore, genome sequence analyses using only one cell have been possible. Nevertheless, we are confident there is merit to cultivation of microbes to help fully explore a more complete range of organisms and the potential that they hold.

\section{DEDICATION}

This paper is dedicated to Professor Satoshi Ōmura, on this opportunity to congratulate him on his receipt of the 2015 Nobel Prize in Physiology or Medicine for his work on the discovery of ivermectin. Most of our work carried out in Kitasato facilities was done so under the guidance or supervision of Professor Satoshi Ōmura, and we express our profound thanks to him for his continual advice and support.

\section{CONFLICT OF INTEREST}

The authors declare no conflict of interest.

\section{ACKNOWLEDGEMENTS}

We thank Drs Masato Iwatsuki, Takuji Nakashima and Yuki Inahashi, Kitasato Institute for Life Sciences, Kitasato University, for secondary metabolite analyses of isolated strains. We would also like to thank the many students, researchers and staff, too numerous to mention by name, who have contributed substantially to this research during the past few decades. Part of this work was financially supported by the Institute for Fermentation, Osaka (IFO), Japan.

1 Bérdy, J. Thoughts and facts about antibiotics: where we are now and where we are heading. J. Antibiot. 65, 385-395 (2012).

2 Newman, D. J. \& Cragg, G. M. Natural products as sources of new drugs from 1981 to 2014. J. Nat. Prod. 79, 629-661 (2016).

3 Bulgarelli, D. et al. Revealing structure and assembly cues for Arabidopsis root-inhabiting bacterial microbiota. Nature 488, 91-95 (2012).

4 Romero, F. M., Marina, M. \& Pieckenstain, F. L. The communities of tomato (Solanum lycopersicum L.) leaf endophytic bacteria, analyzed by 16S-ribosomal RNA gene pyrosequencing. FEMS Microbiol. Lett. 351, 187-194 (2014).

5 Manter, D. K., Delgado, J. A., Holm, D. G. \& Strong, R. A. Pyrosequencing reveals a highly diverse and cultivar-specific bacterial endophyte community in potato roots. Microb. Ecol. 60, 157-166 (2010)

6 Conn, V. M. \& Franco, C. M. Analysis of the endophytic actinobacterial population in the roots of wheat (Triticum aestivum L.) by terminal restriction fragment length polymorphism and sequencing of $16 \mathrm{~S}$ rRNA clones. Appl. Environ. Microbiol. 70, 1787-1794 (2004).

7 Lundberg, D. S. et al. Defining the core Arabidopsis thaliana root microbiome. Nature 488, 86-94 (2012)

8 Coombs, J. T. \& Franco, C. M. Visualization of an endophytic Streptomyces species in wheat seed. Appl. Environ. Microbiol. 69, 4260-4262 (2003).

9 Basil, A. J., Strap, J. L., Knotek-Smith, H. M. \& Crawford, D. L. Studies on the microbial populations of the rhizosphere of big sagebrush (Artemisa tridentate). J. Ind. Microbiol. Biotechnol. 31, 278-288 (2004).

10 Watt, M., Hugenholtz, P., White, R. \& Vinall, K. Numbers and locations of native bacteria on field-grown wheat roots quantified by fluorescence in situ hybridization (FISH). Environ. Microbiol. 8, 871-884 (2006).

11 Janso, J. E. \& Carter, G. T. Biosynthetic potential of phylogenetically unique endophytic actinomycetes from tropical plants. Appl. Environ. Microbiol. 76, 4377-4386 (2010).

12 Qin, S. et al. Isolation, diversity, and antimicrobial activity of rare actinobacteria from medicinal plants of tropical rain forests in Xishuangbanna, China. Appl. Environ. Microbiol. 75, 6176-6186 (2009).

13 Zhao, K. et al. The diversity and anti-microbial activity of endophytic actinomycetes isolated from medicinal plants in Panxi plateau, China. Curr. Microbiol. 62 , 182-190 (2011).

$14 \mathrm{Li}$, J. et al. Isolation and characterization of culturable endophytic actinobacteria associated with Artemisia annua L. Antonie Van Leeuwenhoek 101, 515-527 (2012).

15 Kaewkla, O. \& Franco, C. M. M. Rational approaches to improving the isolation of endophytic actinobacteria from Australian native trees. Microb. Ecol. 65, 384-393 (2013).

16 El-Shatoury, S. A. et al. Generic and functional diversity in endophytic actinomycetes from wild Compositae plant species at South Sinai-Egypt. Res. Microbiol. 164, 761-769 (2013)

$17 \mathrm{Yu}, \mathrm{H}$. et al. Recent developments and future prospects of antimicrobial metabolites produced by endophytes. Microbiol. Res. 165, 437-449 (2010).

18 Gunatilaka, A. A. L. Natural products from plant-associated microorganisms: distribution, structural diversity, bioactivity, and implications of their occurrence. J. Nat. Prod. 69, 509-526 (2006)

19 Golinska, P. et al. Endophytic actinobacteria of medicinal plants: diversity and bioactivity. Antonie Van Leeuwenhoek 108, 267-289 (2015).

20 Firáková, S., Šturdíková, M. \& Múčková, M. Bioactive secondary metabolites produced by microorganisms associated with plants. Biol. Bratisl. 62, 251-257 (2007).

$21 \mathrm{Du}, \mathrm{H}$. J. et al. Allonocardiopsis opalescens gen. nov., sp. nov., a new member of the suborder Streptosporangineae, from the surface-sterilized fruit of a medicinal plant. Int. J. Syst. Evol. Microbiol. 63, 900-904 (2013).

22 Indananda, C. et al. Actinophytocola oryzae gen. nov., sp. nov., isolated from the roots of Thai glutinous rice plants, a new member of the family Pseudonocardiaceae. Int. J. Syst. Evol. Microbiol. 60, 1141-1146 (2010).

23 Quin, S. et al. Plantactinospora mayteni gen. nov., sp. nov., a member of the family Micromonosporaceae. Int. J. Syst. Evol. Microbiol. 59, 2527-2533 (2009).

24 Inahashi, Y., Matsumoto, A., Danbara, H., Ōmura, S. \& Takahashi, Y. Phytohabitans suffuscus gen. nov., sp. nov., an actinomycete of the family Micromonosporaceae isolated from plant roots. Int. J. Syst. Evol. Microbiol. 60, 2652-2658 (2010).

25 Matsumoto, A. et al. Rhizocola hellebori gen. nov., sp. nov., a novel actinomycete of the family Micromonosporaceae containing 3,4-dihydroxydiaminopimelic acid in the cell-wall peptidoglycan. Int. J. Syst. Evol. Microbiol. 64, 2706-2711 (2014).

26 Mingma, R., Tanaka, K., Ōmura, S., Takahashi, Y. \& Matsumoto, A. Actinorhabdospora filicis gen. nov., sp. nov., a new member of the family Micromonosporaceae. Int. J. Syst. Evol. Microbiol. 66, 3071-3077 (2016).

27 Inahashi, Y., Matsumoto, A., Ōmura, S. \& Takahashi, Y. Streptosporangium oxazolinicum sp. nov., a novel endophytic actinomycete producing new antitrypanosomal antibiotics, spoxazomicins. J. Antibiot. 64, 297-302 (2011).

28 Matsumoto, A., Fukuda, A., Inahashi, Y., Ōmura, S. \& Takahashi, Y. Actinoallomurus radicium sp. nov., isolated from the roots of two plant species. Int. J. Syst. Evol. Microbiol. 62, 295-298 (2012).

29 Koyama, R., Matsumoto, A., Inahashi, Y., Ōmura, S. \& Takahashi, Y. Isolation of actinomycetes from the root of the plant, Ophiopogon japonicus, and proposal of two new species, Actinoallomurus liliacearum sp. nov. and Actinoallomurus vinaceus sp. nov. J. Antibiot. 65, 335-340 (2012).

30 Inahashi, Y., Matsumoto, A., Ōmura, S. \& Takahashi, Y. Phytohabitans flavus sp. nov., Phytohabitans rumicis sp. nov. and Phytohabitans houttuyneae sp. nov., isolated from plant roots and emended description of the genus Phytohabitans. Int. J. Syst. Evol. Microbiol. 62, 2717-2723 (2012).

31 Mingma, R., Duangmal, K. Ōmura, S., Takahashi, Y. \& Matsumoto, A. Three novel species of the genus Kibdelosporangium; Kibdelosporangium kanagawaense sp. nov., Kibdelosporangium rhizosphaerae sp. nov. and Kibdelosporangium rhizovicinum sp. nov. Int. J. Syst. Evol. Microbiol. (accepted for publication).

32 Pozzi, R. et al. The genus Actinoallomurus and some of its metabolites. J. Antibiot. 64, 133-139 (2011).

33 Tiwari, K. \& Gupta, R. K. Rare actinomycetes: a potential storehouse for novel antibiotics. Crit. Rev. Biotechnol. 32, 108-132 (2012).

$34 \mathrm{Liu}$, W. et al. Rapid PCR amplification of minimal enediyne polyketide synthase cassettes leads to a predictive familial classification model. Proc. Natl Acad. Sci. USA 100, 11959-11963 (2003).

35 Ayuso-Sacido, A. \& Genilloud, O. New PCR primers for the screening of NRPS and PKS-I systems in actinomycetes: detection and distribution of these biosynthetic gene sequences in major taxonomic groups. Microb. Ecol. 49, 10-24 (2005). 
36 Roller, C., Ludwig, W. \& Schleifer, K. H. Gram-positive bacteria with a high DNA G+C content are characterized by a common insertion within their 23S rRNA genes. J. Gen. Microbiol. 138, 1167-1175 (1992).

37 Stach, J. E., Maldonado, L. A., Ward, A. C., Goodfellow, M. \& Bull, A. T. New primers for the class Actinobacteria: application to marine and terrestrial environments. Environ. Microbiol. 5, 828-941 (2003).

38 Niemhom, N., Chutrakul, C., Suriyachadkun, C. \& Thawai, C. Phytohabitans kaempferiae sp. nov., an endophytic actinomycete isolated from the leaf of Kaempferia larsenii. Int. J. Syst. Evol. Microbiol. 66, 2917-2922 (2016).

39 Inahashi, Y. et al. Actinoallolides A-E, new anti-trypanosomal macrolides, produced by an endophytic actinomycete, Actinoallomurus fulvus MK10-036. Org. Lett. 17, 864-867 (2015).

40 Nakashima, T. et al. Trehangelins A, B and C, novel photo-oxidative hemolysis inhibitors produced by an endophytic actinomycete, Polymorphospora rubra K07-0510. J. Antibiot. 66, 311-317 (2013).
41 Inahashi, Y. et al. Spoxazomicins A-C, novel antitrypanosomal alkaloids produced by an endophytic actinomycete, Streptosporangium oxazolinicum $\mathrm{K} 07-0460^{\top}$. J. Antibot. 64 303-307 (2011).

42 Nakashima, T. et al. Mangromicins A and B: structure and antitrypanosomal activity of two new cyclopentadecane compounds from Lechevalieria aerocolonigenes K10-0216. J. Antibiot. 67, 253-260 (2014).

43 Iwatsuki, M. et al. Lariatins, novel anti-mycobacterial peptides with a lasso structure, produced by Rhodococcus jostii K01-B0171. J. Antibiot. 60, 357-363 (2007).

$44 \mathrm{Chiba}, \mathrm{H}$. et al. Actinohivin, a novel anti-HIV protein from an actinomycete that inhibits syncytium formation: isolation, characterization, and biological activities. Biochem. Biophys. Res. Commun. 282, 595-601 (2001).

45 Konishi, M. et al. Dynamicin A, a novel antibiotic with the anthraquinone and 1,5-diyn3-ene subunit. J. Antibiot. 42, 1449-1452 (1989).

46 Hanada, M. et al. Maduropeptin, a complex of new macromolecular antitumor antibiotics. J. Antibiot. 44, 403-414 (1991). 